\title{
A MODALIDADE DE LICITAÇÃO "DIÁLOGO COMPETITIVO" NA REDUÇÃO DE CONFLITOS EM ÂMBITO ADMINISTRATIVO
}

\author{
André Lemuel Ferreira Krieguer ${ }^{1}$ \\ Anny Caroline Dias ${ }^{2}$ \\ Pedro Willimann dos Anjos ${ }^{3}$ \\ Sabrina Frigotto ${ }^{4}$ \\ Gustavo Marcondes 5 \\ Recebido em 01/12/2021 \\ Aceito em 20/12/2021
}

\begin{abstract}
RESUMO
O presente trabalho tem como foco introduzir a discussão acerca do diálogo competitivo ao âmbito acadêmico. Pois além de ser uma nova forma de licitar introduzida pela Lei 14.133, é também um meio alternativo de resolução de conflitos. Outros ramos do direito já utilizam ferramentas como a conciliação, mediação, arbitragem, autodefesa, autocomposição, acordo de não persecução, etc. Entretanto o administrador não detinha ferramentas que possibilitassem uma interação mais ativa nas etapas do acordo. Tal parâmetro, se bem utilizado, fará com que as contratações junto a Administração Pública ocorram de forma mais consciente e desburocratizada, visando sempre o interesse da coletividade. Quanto aos aspectos metodológicos, a pesquisa foi de natureza básica, com abordagem qualitativa, objetivo exploratório e bibliográfico do tipo narrativo.
\end{abstract}

PALAVRAS-CHAVE: Diálogo Competitivo. Lei 14.133. Resolução de Conflitos.

\section{THE BIDDING MODALITY "COMPETITIVE DIALOGUE" IN THE REDUCTION OF}

ADMINISTRATIVE CONFLICTS

\section{ABSTRACT}

The present article is focused on introducing the discussion about competitive dialogue to the academic environment. As well as being a new form of bidding introduced by Law 14.133 , it is also an alternative means of conflict resolution. Other branches of law already use tools such as conciliation, mediation, arbitration, self-defence, self-composition, nonprosecution agreement, etc. However, the administrator did not have tools that enabled a more active interaction in the stages of the agreement. Such parameter, if properly used,

\footnotetext{
${ }^{1}$ Acadêmico da $6{ }^{\text {a }}$ fase do curso de Direito da Universidade Alto Vale do Rio do Peixe Campus Fraiburgo. E-mail: andrelfkrieguer@gmail.com.

${ }^{2}$ Acadêmica da $6^{\text {a }}$ fase do Curso de Direito da Universidade Alto Vale do Rio do Peixe Campus Fraiburgo. Email: annycarolinedias25@gmail.com.

${ }^{3}$ Acadêmico da 6 a fase do curso de Direito da Universidade Alto Vale do Rio do Peixe Campus Fraiburgo. E-mail: pwillemann32@gmail.com.

${ }^{4}$ Acadêmica da $6^{\text {a }}$ fase do Curso de Direito da Universidade Alto Vale do Rio do Peixe Campus Fraiburgo. Email: sabrinafrigotto19@gmail.com.

${ }^{5}$ Professor do curso de Direito da Universidade Alto Vale do Rio do Peixe - UNIARP. Especialista em Direito do Trabalho e Previdência Social. E-mail: gustavomarcondes@uniarp.edu.br.
} 
will make hiring with the Public Administration occur in a more conscious and unbureaucratic way, always aiming at the interest of the community. As for the methodological aspects, the research was of a basic nature, with a qualitative approach, exploratory and bibliographic objective of the narrative type.

Keywords: Competitive Dialogue. Law 14.133. Conflict resolution.

\section{INTRODUÇÃO}

Durante o período de vigência da Lei 8.666/93 ocorreram várias alterações no que concerne às licitações. Um exemplo é a modalidade pregão, adicionada pela Lei 10.520/2002, a qual abriu a possibilidade da forma licitatória eletrônica.

A partir da publicação da nova normativa (Lei 14.133/21), esta conviverá por dois anos com a antiga, para que assim haja a necessária adaptação por parte da administração pública.

Anteriormente ao ano de 2021, haviam seis modalidades de licitação, sendo elas: concorrência, tomada de preços, convite, concurso, leilão e pregão. A Lei 14.133 excluiu de seu rol a tomada de preços e o convite, como também deu margem a utilização de uma nova forma: o diálogo competitivo.

É conhecido também como diálogo concorrencial, destinado a contratações mais complexas em âmbito administrativo. As quais exigem o diálogo como meio de resolver os principais conflitos neste âmbito.

Várias áreas do direito já possuíam bem consistente a questão de formas menos burocráticas de resolver as suas questões. Em âmbito cível destacam-se a conciliação, a mediação e a arbitragem; na área trabalhista é comum que se ouça falar em autocomposição e autodefesa; no direito criminal recentemente criou-se a figura do acordo de não persecução penal.

Todavia, quando se tratam das contratações públicas pensar em formas alternativas de resolução de conflitos é um tanto desafiador. É claro que o Administrador não pode beneficiar um ou outro licitante ou contratar ao seu bel-prazer, não é este o objetivo da nova modalidade.

O presente trabalho acadêmico tem, portanto, o escopo de analisar o diálogo competitivo e suas particularidades, a fim de apresentar os prós e contras deste instituto. E, por fim, ser capaz de dizer se ele representa ou não uma forma eficiente de dirimir os conflitos licitatórios.

Para que fossem alcançados todos os objetivos propostos, contou-se com a pesquisa em bibliografia atual e conceituada, explanando pontos divergentes na busca de um resultado comum, qual seja: o bem-estar coletivo. 


\section{MODELOS LICITATÓRIOS}

A lei de 14.133/2021 surgiu depois de mais de 25 anos da lei vigente 8.666/93, esta sofreu ao longo desse tempo inúmeras alterações. Destaca-se dentre essas alterações, a Lei do Pregão (Lei nº 10.520/2002), que introduziu uma nova modalidade de licitação, mais célere e que abriu a possibilidade à forma eletrônica de contratações. (LOPES, 2021)

O legislador previu que a Lei n. 14.133/2021, uma vez sancionada e publicada, conviverá por dois anos com as leis que compõem o regime antigo. As Leis n. 8.666/1993, 10.520/2002, e os dispositivos da Lei n ${ }^{\circ} 12.462 / 2001$ que versam sobre o Regime Diferenciado de Contratações Públicas somente serão revogadas depois de 2 (dois) anos da publicação da Lei n. 14.133/2021. Ou seja, haverá um período de convívio entre os regimes antigo e novo de licitação e contratação (NIEBUHR, et. al. 2021).

Portanto, durante os dois anos que seguem à publicação da Lei n. 14.133/2021 a Administração dispõe de três opções: (i) aplicar o regime novo, (ii) aplicar o regime antigo ou (iii) alternar os regimes, ora promovendo licitações sob o regime antigo e ora promovendo licitações sob o regime novo (NIEBUHR, et. al. 2021, pag. 08).

A Lei nº 8.666/93 previa cinco modalidades de licitação, sendo elas, concorrência, tomada de preços, convite, concurso e leilão. As três primeiras, dedicadas à compra, seja de obras, serviços ou bens, diferenciavam-se pelo valor estimado da licitação. O concurso seleciona trabalhos técnicos, científicos ou artísticos por meio de premiações ou remuneração aos vencedores, já o leilão é destinado venda ou alienação de bens (LOPES, 2021).

A lei 10.520/02 que incluiu a modalidade Pregão, deixou de orientar-se pelo valor, mudou de forma profunda o rito de licitação, trazendo a inversão de fases, neste caso, primeiro tinha-se a disputa de preços entre os interessados e julgamento das propostas e analisavam-se os documentos de habitação somente do vencedor (LOPES, 2021).

As modalidades de licitação da lei 14.133/21 estão previstas em seu art. 28 e incisos, são eles: o Pregão, Concorrência, Concurso, Leilão e Dialogo Competitivo.

\footnotetext{
A nova lei, nos arts. 28 a 32, extingue as modalidades de tomada de preços e convite, já pouco utilizadas na prática desde o advento do pregão, em especial o de forma eletrônica, e mantém as modalidades de pregão, concorrência, concurso e leilão. Uma grande diferença nessas modalidades até então regidas pela lei de 1993 é que agora elas também assumirão o formato eletrônico como regra (o que no pregão já é uma realidade), bem como passarão a ter o rito do pregão (que é o mesmo do RDC) como a regra, ou seja, primeiro julgam-se as propostas para depois habilitar o licitante. $\mathrm{O}$ RDC também deixa de existir, tendo vários de seus procedimentos absorvidos pelas modalidades mencionadas (LOPES, 2021).
} 
A modalidade de licitação denominada diálogo competitivo é conhecida também como diálogo concorrencial, é definido no inciso XLII do art. $6^{\circ}$ da Lei 14.133/2021. De forma geral, o diálogo competitivo destina-se as contratações complexas da Administração Pública, tendo o diálogo como instrumento com a iniciativa privada (REMÉDIO, 2021, p. 10)

Outra mudança trazida pela nova lei é a vigência dos contratos, que anteriormente duravam até 12 meses, com algumas exceções quanto aos serviços de prestação continuada que poderiam ser por até 60 meses. Agora os contratos poderão ser firmados com vigência inicial de até 5 anos para os serviços contínuos, podendo ser prorrogados por até 10 anos. Há também previsões de contratações com prazos iniciais de 10 e com prazos entre 10 e 35 anos para os que gerem receita para a Administração ou os de eficiência conforme haja ou não investimento (LOPES, 2021).

\section{A CRESCENTE BUSCA POR FORMAS ALTERNATIVAS DE RESOLUÇÃO DE CONFLITOS}

O ser humano, desde que começou a se organizar em comunidades, enfrenta conflitos sociais e tem a necessidade de encontrar um meio apto a saná-los. Na atualidade tem-se a concepção de que o Estado deve prover condições básicas para que todos, igualmente, possuam formas para acessar o judiciário, para assim, alcançarem a resolução da lide pretendida, seja ela, cultural, social ou econômica (ZANINI, 2017).

Esse acesso à justiça, como elencado em nossa legislação nacional, é garantido pela Constituição Federal de 1988, na forma do inciso XXXV, artigo 5, “a lei não excluirá da apreciação do Poder Judiciário, lesão ou ameaça a direito" (BRASIL, 1988).

Entretanto o Poder Judiciário não consegue, de forma célere, julgar todas as causas. Razão pela qual optou-se por criar formas alternativas de resolução de conflitos. Em âmbito cível é muito comum que ouça falar nas figuras da conciliação, mediação e arbitragem:

\footnotetext{
A conciliação, a mediação e a arbitragem possuem características próprias e são, especialmente, diferenciadas pela abordagem do conflito. O papel desempenhado pela conciliação, pela mediação e pela arbitragem dentro do sistema processual tradicional sempre foi muito tímido, talvez pela grande influência da cultura do litígio (PISKE, 2010, p. 10).
}

Neste contexto, dentre as resoluções, é de maior interesse a conciliação, observando as vias conciliativas que revestem a sociedade contemporânea, considerada pelo legislador como uma das mais relevantes alternativas. Entretanto, é basilar que o juiz seja um pacificador social que auxilie no processo em busca de decisões mais justas, efetivas e eficientes, atuando também 
como conciliador (PISKE, 2010).

Tais formas são muito impulsionadas no âmbito cível, mas as alternativas amigáveis não são exclusivas desse ramo do direito. Na seara trabalhista as partes são sempre incentivadas a realizares suas propostas e fecharem um acordo em audiência, existem inclusive os meios da autodefesa, autocomposição e heterocomposição, na alçada criminal criou-se recentemente a figura do acordo de não persecução penal. Todas estas ferramentas, a seu modo contribuem para a construção de um sistema de justiça mais célere.

Entretanto, quando se trata de administração pública, vem desde logo a ideia de algo burocrático e de certa forma mais lento. Assim, com a nova Lei de Licitações, que trouxe a figura do diálogo competitivo, o cenário tende a alterar-se para melhor, com tão rica ferramenta de negociações.

Nas entrelinhas, o que está em evidência, são princípios do Estado mínimo, visando a contribuição dos entes privados para as soluções de dilemas sociais e do Estado, trazendo em sua íntegra, a competição, inovação, redução da corrupção e novas possibilidades mais vantajosas. Auxilia ainda no contexto de segurança jurídica, transformando os contratos públicos e processos licitatórios em uma solução mais rápida e eficiente, melhorando com a prestação de serviços à sociedade.

\section{O DIÁLOGO COMPETITIVO NA REDUÇÃO DOS CONFLITOS LICITATÓRIOS}

O Diálogo Competitivo é um novo modelo de licitação que foi introduzido pela Lei $\mathrm{n}^{\circ}$ 14.133/21, que é uma lei geral sobre licitações e contratos que substituirá a Lei $\mathrm{n}^{\circ}$ 8.666/93. Trata-se de uma forma de licitação para contratação de obras, serviços e licitações, aplicável aos contratos que acumulam:

\footnotetext{
Inovação técnica ou tecnológica; Falta de soluções disponíveis no mercado; Impossibilidade de a Administração definir com precisão as especificações técnicas do objeto a ser contratado; ou necessidade de definir meios e alternativas técnicas às soluções já definidas e à estrutura jurídica e financeira do contrato (FERNANDES, et. al. 2021, n.p.).
}

Será utilizado para contratações de objetos complexo, que a Administração não possui conhecimento suficiente para identificar a melhor solução e descrevê-la para uma disputa nas demais modalidades, sendo necessária a colaboração do mercado na identificação e desenvolvimento das possíveis alternativas (LOPES, 2021).

O diálogo competitivo está restrito a contratar objetos que envolvam a inovação tecnológica ou técnica, a impossibilidade de órgão ou entidade ver atendida a sua necessidade pelas soluções disponíveis no mercado, ou a impossibilidade de definir e 
identificar os meios e as alternativas que consigam suas necessidades. A Administração pode abrir edital informando, em sítio eletrônico próprio, as condições e necessidades para a solução e só encerrar os diálogos quando, de forma documentada em atas e gravações, identificar que o melhor interesse e solução foi alcançada, dessa forma, encerra-se o diálogo competitivo com a publicação das atas e gravações pela comissão de contratação, que deve ser composta de 3 (três) servidores efetivos ou empregados públicos pertencentes ao quadro da Administração, sendo vedada a contratação de profissionais para assessoramento técnico da comissão (LIMA, et. al. 2021, n.p.).

A modalidade se divide em duas fases, a primeira se trata do diálogo, onde a administração conhecerá as soluções disponíveis e determinará a solução mais favorável com base no diálogo e na negociação, bem como na fase da competição, sendo que as empresas participantes da fase anterior apresentarão as suas sugestões para a solução escolhida.

Para Zago (2021), a fase de diálogo inicia-se com a constituição da comissão de recrutamento (composta por colaboradores de longa data, mas com assessoria de consultores técnicos contratados) e a emissão de edital que definirá os requisitos e condições de atuação da entidade competente. A partir daí as reuniões com as partes interessadas permitirão ao governo compreender as especificidades, vantagens e desvantagens das soluções apresentadas e, a partir daí, decidir sobre a solução mais vantajosa e, chegando ao fim da fase de diálogo.

A fase do concurso inicia-se com a publicação de um novo edital, no qual a administração irá especificar o objeto (passa a explicar todas as características e condições de fornecimento da solução técnica a disponibilizar) e determinar a melhor proposta estipulada pela lei-padrão. Todas as partes interessadas que participam da etapa de diálogo podem participar da competição (ZAGO, 2021).

Para que seja feita a escolha da solução mais adequada às suas necessidades, a administração tem duas opções, a saber: escolher totalmente uma solução proposta por um participante do diálogo, ou construir uma nova solução adicionando as ideias e pesquisas propostas por diferentes participantes (AVELAR, 2021).

Segundo AVELAR (2021), a primeira opção é alvo de críticas, no que concerne ao possível favorecimento de um participante em detrimento de outro, e a segunda alternativa relacionada à construção de uma solução "conjunta", levanta preocupações sobre a confidencialidade, o que é denominado atualmente de "Cherry-Picking".

O cherry-picking é justamente o risco de seleção arbitrária de aspectos apresentados pelos participantes durante a fase de diálogo para a construção da solução adequada. E associado a esse risco está a preocupação dos participantes de que soluções inovadoras ou informações sensíveis que tenham apresentado à Administração Pública em caráter de confidencialidade sejam divulgadas aos demais participantes (AVELAR, 2021, n.p.). 
Assim entende-se que, se a legislação não abordar adequadamente tais riscos, pode impedir os participantes de proporem soluções durante a fase de diálogo. Isso pode ser devido a leis pouco claras que impedem o diálogo competitivo de desempenhar seu papel principal, efeito prejudicial de adquirir a expertise do setor privado (AVELAR, 2021).

Em relação aos meios de soluções de conflitos, a nova modalidade de licitação, traz um mecanismo de otimização das complexas contratações realizadas pela administração pública, por meio do diálogo do órgão administrativo com a iniciativa privada.

Destarte que, em tese, por meio do diálogo competitivo, a Administração definirá os requisitos a serem utilizados antes da seleção dos licitantes, definindo também, suas necessidades, com o objetivo de obter informações dos privados, abrindo alternativas em busca da solução mais adequada ao problema do Estado (MARTINEZ; COSTA, 2021).

Cabe a referência, no artigo 32, inciso I da nova lei de licitações 14.133/21, estabelece:

\begin{abstract}
Art. 32. A modalidade diálogo competitivo é restrita a contratações em que a Administração:

I - vise a contratar objeto que envolva as seguintes condições: a) inovação tecnológica ou técnica; b) impossibilidade de o órgão ou entidade ter sua necessidade satisfeita sem a adaptação de soluções disponíveis no mercado; e c) impossibilidade de as especificações técnicas serem definidas com precisão suficiente pela Administração; II - verifique a necessidade de definir e identificar os meios e as alternativas que possam satisfazer suas necessidades, com destaque para os seguintes aspectos: a) a solução técnica mais adequada; b) os requisitos técnicos aptos a concretizar a solução já definida; c) a estrutura jurídica ou financeira do contrato (BRASIL, 2021).
\end{abstract}

A lei em destaque, define, que a modalidade do diálogo competitivo, deve ser empregada somente em casos de inovação tecnológica, reduzindo assim as informações entre o ente público e privado, abrindo janelas de flexibilização do processo licitatório, de modo que os particulares oferecem diferentes opções de soluções de contratação para a Administração.

Nas entrelinhas, o que está em evidência, são princípios do Estado mínimo, visando a contribuição dos entes privados para as soluções carentes da sociedade e Estado, trazendo em sua íntegra, a competição, inovação, redução da corrupção e novas possibilidades vantajosas de contratação.

Como Friedman explana a respeito do livre mercado, há de perceber a sua importância também para os entes estatais, que representam a sociedade, correlacionando as inovações legislativas:

O uso amplo do mercado reduz a tensão aplicada sobre a intrincada rede social por tomar desnecessária a conformidade, com respeito a qualquer atividade que patrocinar. Quanto maior o âmbito de atividades cobertas pelo mercado, menor o número de questões para as quais serão requeridas decisões explicitamente políticas e, portanto, para as quais será necessário chegar a uma concordância. Como contrapartida, quanto menor o número de questões sobre as quais será necessária a 
concordância, maior probabilidade de obter concordâncias e manter uma sociedade livre.

$[\ldots]$

O monopólio implica ausência de alternativas e inibe, portanto, a liberdade efetiva da troca (FRIEDMAN, p. 35, 1962).

Portanto, observa-se a relevância da nova lei de licitações em foco a alternativas de resolução de conflitos plausíveis para a Administração Pública. O que vem ao encontro do contexto de segurança jurídica, transformando os contratos públicos e processos licitatórios em uma solução mais rápida e eficiente, de forma a melhorar a prestação de serviços à sociedade.

\section{CONSIDERAÇÕES FINAIS}

Diante de todo o conteúdo apresentado e discutido foi possível perceber que o diálogo competitivo é uma excelente alternativa criada para resolver as demandas mais complexas no que tange a administração pública, nas quais esteja presente incerteza ou indeterminação quanto a solução a ser alcançada.

Com a divisão em etapas é possível que os licitantes façam ofertas e discussões do que imaginam ser adequado a efetiva resolução da demanda a eles posta. E mesmo que o setor público não aprove nenhuma das propostas, as ideias em si podem ser utilizadas em prol do bem coletivo.

Entretanto, a modalidade convite, agora sobrepujada pela nova lei de licitações também representava um bom modo de licitar. O que transparece, portanto é a necessidade de se dar ao administrador maior autonomia no que tange a este aspecto.

Pois o diálogo competitivo, da mesma forma que seu primo o convite, exige que o próprio administrador selecione as pessoas físicas ou jurídicas que farão parte das negociações. Mas se este aspecto servir de base para a demonização do diálogo, esta será apenas uma modalidade legada ao esquecimento.

Isso porque, na teoria se fala muito e interminavelmente na eficiência e na busca por uma menor morosidade. Todavia os que tentam este caminho são muitas vezes surpreendidos por uma Ação Civil Pública sob o frágil fundamento de valorização de uma das partes em detrimento de outra.

Então, é possível afirmar que, se bem utilizada a ferramenta do diálogo competitivo, esta tende a ser uma ótima estratégia a evitar conflitos em âmbito licitatório. Desde que seja concedida a administração o arbítrio de tomar suas próprias decisões de maneira segura. 


\section{REFERÊNCIAS BIBLIOGRÁFICAS}

AVELAR, Mariana Magalhães. 7 pontos do Diálogo competitivo que você precisa saber. Observatório da Nova Lei de Licitações. Disponível em:

$<$ http://www.novaleilicitacao.com.br/2021/03/31/7-pontos-do-dialogo-competitivo-que-voceprecisa-saber/>. Acesso em 30 set. 2021.

BRASIL. Secretaria Geral. Brasília, DF, 2021. Disponível em: <http://www.planalto.gov.br/ccivil_03/_ato2019-2022/2021/lei/L14133.htm>. Acesso em 30 set.2021.

FRIEDMAN, Milton. Capitalismo e liberdade. São Paulo: Nova Cultural, 1985.

FULLER, Ariane; FERNANDES, Diego Gonçalves. ESTAMOS PREPARADOS PARA O DIÁLOGO COMPETITIVO?. Inteligência Jurídica. Disponível em:

$<$ https://www.machadomeyer.com.br/pt/inteligencia-juridica/publicacoes-ij/contenciosoarbitragem-e-solucao-de-disputas-ij/estamos-preparados-para-o-dialogo-competitivo>. Acesso em 03 out.2021.

LIMA, Raphael Silva de. PEREIRA, Damiane de Souza. Victor Hugo da Silva. As modalidades de licitação previstas na lei n⿳10.133 de 2021 e a governança. Revista Científica Multidisciplinar Núcleo do Conhecimento. Ano 06, Ed. 05, Vol. 04, pp. 104-112. Maio de 2021. Disponível em:

$<$ https://www.nucleodoconhecimento.com.br/administracao/licitacao-previstas $>$. Acesso em: 13 set. 2021.

LOPES, Virgínia Bracarense. A Nova Lei de Licitações: 5 mudanças trazidas pela norma aprovada. 2021. Disponível em: 〈http://anesp.org.br/todas-as-noticias/nova-lei-de-licitacoes〉. Acesso em: 13 set. 2021.

MARTINEZ, Ana Carolina; COSTA, Leonardo Dalla. Meios de resolução de conflitos e diálogo competitivo na lei 14.133/21. Disponível em:

$<$ https://www.migalhas.com.br/depeso/344756/meios-de-resolucao-de-conflitos-e-dialogocompetitivo-na-lei-14-133-21>. Acesso em: 25 set. 2021.

MEERHOLDZ, André. O diálogo competitivo na nova Lei de Licitações. ConJur.

Disponível em: <https://www.conjur.com.br/2021-mai-07/meerholz-dialogo-competitivo-leilicitacoes>. Acesso em: 04 out. 2021.

NIEBUHR, Joel de Menezes, et. al. Nova Lei de Licitações e Contratos Administrativos. 2 ed. Curitiba: Zênite, 2021. Disponível em:

$<$ https://repositorio.ufsc.br/bitstream/handle/123456789/222331/ebook\%20-

$\% 20$ nova\%20lei\%20de\%20licitacoes $\% 20 \mathrm{e} \% 20$ contratos\%20administratos\%20-

$\% 202$ a\%20edicao\%20-\%20zenite.pdf?sequence=1>. Acesso em: 13 set. 2021.

PISKE, Oriana. Formas Alternativas de Resolução de Conflito. Disponível em:<https://bdjur.tjdft.jus.br/xmlui/bitstream/handle/123456789/3141/Artigo\%20$\% 20$ in $\%$ E9dito\%20-

$\% 20 \%$ 20FORMAS\%20ALTERNATIVAS\%20DE\%20RESOLU\%C7\%C3O\%20DE\%20CO

NFLITO\%20-\%2025\%20p\%E1g.pdf?sequence=1>. Acesso em: 25 set. 2021. 
REMÉDIO, José Antônio. Lei de licitações e contratos administrativos (lei 14.133/2021): o diálogo competitivo como nova modalidade de licitação. Revista de Direito Administrativo e Gestão Pública. v. 7. p. 01 - 21. 2021. Disponível em:

<file:///C:/Users/Usuario/Downloads/7568-22519-1-PB.pdf>. Acesso em 13 set. 2021.

SOARES, Enmanuely Sousa. Resolução de conflitos. Quais as alternativas. Disponível em: <https://jus.com.br/artigos/63506/resolucao-de-conflitos-quais-as-alternativas>. Acesso em: 26 set. 2021.

ZAGO, Maria Fontão. Diálogo competitivo: Para o quê e para quem?. Migalhas. Disponível em: <https://www.migalhas.com.br/depeso/346368/dialogo-competitivo-para-o-que-e-paraquem>. Acesso em: 04 out. 2021.

ZANINI, Ana Carolina. O Acesso à justiça e as formas alternativas de resolução de conflitos à luz do Novo Código de Processo Civil. Disponível em:

<http://revista.direitofranca.br/index.php/refdf/article/view/404>. Acesso em: 20 out. 2021. 